\title{
Peer group influence on academic performance of undergraduate students in Babcock University, Ogun State
}

\author{
Filade, Bankole Adeyemi ${ }^{1 *}$, Bello, Alice Adejoke ${ }^{1}$, Uwaoma, Christiana $0 .{ }^{1}$, Anwanane, Bidemi \\ Bassey $^{2}$ and Nwangburuka, Kemi ${ }^{3}$
}

${ }^{1}$ Department of Education, Babcock University, Ilishan, Ogun State, Nigeria.

${ }^{2}$ Student Support Center, Babcock University, llishan, Ogun State, Nigeria.

${ }^{3}$ Student Development Division, Babcock University, Ilishan, Ogun State, Nigeria.

Accepted 9 May, 2019

\begin{abstract}
This study surveyed the influence of peer group on academic performance of undergraduate students in selected departments in Babcock University, Ogun State. Peer group plays a large role in the social, emotional and academic development of students; therefore, understanding the prospects and challenges of peer group is crucial for the productivity of educational processes and the organizational design of school systems in order to improve student's academic performance. The study adopted mixed method design incorporating descriptive survey and ex post facto designs. Questionnaire was administered to one hundred and sixteen (116) students drawn from five (5) departments in the School of Education and Humanities. The number was derived from the totality of 300 level students of each department of the School using stratified random sampling method. The data generated from the study were analyzed using Pearson Product Moment Correlation Coefficient and Linear Regression Analysis to test the null hypotheses at 0.05 significant level. The result of this study revealed that, peer group has significant influence on academic performance of undergraduate students. Also, there is significant relationship between peer group and academic performance of students. Sequel to these findings, the researcher therefore recommended that, there is need for teacher to have greater supervision and regulations on students while they are in school, this will enhance the type of group they belong to. The government and ministry of education in all levels should ensure that trained counselors are posted in all schools and colleges so as to provide preventive counseling services and modify the behaviors of students who perchance have been negatively influenced by peers. Also, School counselors should play a prominent and leading role in the matter of peer group influence by organizing lectures, seminars, career talk and symposiums that can create positive awareness on influence of peer group on academic performance of undergraduate students.
\end{abstract}

Keywords: Peer group, academic performance, undergraduate students.

*Corresponding author. E-mail: koleyemi2005@yahoo.com.

\section{INTRODUCTION}

Academic activities are directed towards ensuring that students gain mastery of educational objectives. In schools, the extent to which these objectives have been met is determined greatly by the interaction of peer groups which could possibly reflect in student's academic performance. Peer group play a large role in the social, emotional and academic development of students. Allen in Steinberg (2005) maintains that peer group influence begins at an early age and increases through the teenage years. Thus, understanding the prospects and challenges of peer group is crucial for the productivity of educational processes and the organizational design of 
school systems in order to improve student's academic performance.

Hamm et al. in Lavy and Schlosser (2007), argued that, "for many students, friendships are critical interpersonal vehicle that move them towards psychological growth and maturity, allowing social compassion which influences the development of self-evaluation". The above statement suggests strongly, the unprecedented effect of peer group in almost all facet of adolescent's growth. Such effect could be seen in social and emotional lives of young people, which does not end at the above mentioned, but could also manifest in their attitude towards educational activities and careful consideration of these elements has shown that they reflect in the academic performance of students.

However, Castrogiovanni (2002) defined peer group as a small group of similar age, fairly close friends, sharing the same activities. In its most acceptable form, peer group is a healthy coming-of age intermediary, by which youth grasp negotiating skills and learn to deal with challenges and to solve problems in a social context. Peer group can also act as positive role model, for example, if one is involved with a group of people that are ambitious and working hard to attain high academic goals, one might feel pressured to follow suit to avoid feeling excluded from the group.

A negative peer influence could be seen as one of the militating forces why most student record poorly in academic performance, the reason for this is not farfetched: they spend large amount of time in extra curriculum. More often than none, academic priorities are neglected and thus academic performance grossly affected.

Academic performance refers to excellence in all academic discipline. Steinberg (2005) posits that academic performance encompasses students' ability and performance; it is multi-dimensional; it is intricately associated to human growth and cognitive, emotional and social physical development. Academic performance also refers to how well a student is accomplishing his tasks and studies. There should be a interrelated relationship between peer group and academic performance. It was believed that student's academic performance correlates with the group he or she belongs. Peer Influence can be either positive or negative. If a student is influenced negatively by peer, it affects his or her academic performance. Nevertheless, stronger student do have an impact on their peers and actually help improve their overall academic performance. Conversely, positive peer influence on academic performance depends on person's self-identity, self-esteem and self-reliance. Peer influence can as well inspire student's academic vigor and motivation for achievement (Lashbrook, 2000).

Peer relations are never more prominent than in adolescence which falls within the age group under this study. They spend more time than adults interacting with peers and recording a very high degree of happiness in peer contexts, while giving the greatest priority to peer norms for behavior (Brown and Larson, 2009). This developmental stage in affiliation motivation appears to be highly preserved across peers.

Moreover, several developmental studies on adolescents indicated that, relative to children and adults, they are sensitive and at a high response to a variety of social stimuli such as facial expressions and social feedback (Burnett et al., 2011). However, this evidence for hypersensitivity to social stimuli suggests that this age group may be more likely be exposed to either positive or negative peer stimuli in decision-making scenarios, thus setting the stage for a hyperbolic approach sensitization effect of peer context on decision making. It is well established that undergraduate students are more likely than adults to take risks, as revealed by elevated rates of experimentation with alcohol, tobacco, and drugs, unprotected sexual activity, violent and non - violent crime, and reckless driving (Steinberg, 2008). In fact, they actually possess the knowledge, values, and processing competence to evaluate risky decisions as proficiently as adults do (Reyna and Farley, in Bankole and Ogunsakin, 2015).

According to Olalekan (2016), it is generally observed that peer group has a lot of influence on students. This is seen from the role played by the peer group in the life and learning of a child, evidence abound that students feel more comfortable and relaxed among fellow students. A child who is brilliant and surrounded by dull friends would lose interest in learning. On the other hand, a peer group which is prone to study would have positive effect on a dull member towards learning and stimulate his/her interest on learning. Katz in Olalekan (2016) wrote that the nature of a peer group determines the impact on the motivation of and achievements of its member. He further suggests that one group may have a negative impact on its members while the other may have positive impact on its members as well.

The question at this point is, how many of the young people have the will power to choose a group that thus impact positively on them? However, the attractive nature and the morals of the group determine whether a group is likely to have positive or negative impact on members' motivation and achievement. If the atmosphere of the group is warm, understanding and supportive, the group influence, task performance and achievement will most likely be positive. A hostile group will constantly, mostly such that does not place prominence to academics will frustrate and produce a negative impact not only on the member's growth and behavior but also on their drive to studies and academic achievement. Conversely, the kind of person a student is shows the type of group he or she is most likely to join. In the same vein Festigen as quoted in Lavy and Schlosser (2007) also noted that imitation of behaviors in a group occurs when a person acts in a way that is likely to be joined by the rest of the group. Students who are playful but have academic traits should 
be encouraged to join a study inclined group.

Stressing the positive benefits of a group, Bandura in Olalekan (2016), noted that through observing and imitating the behavior of others, learners can avoid much wasteful random behavior and come close to reproducing the behaviors of which members are recognized. A student may not be dull but playful. If he is well monitored and he falls into a group of brilliant students who are not playful, he imitates them and this changes his attitude towards learning for better. In the same vein a study by Bankole and Ogunsakin (2016) investigated the influence of peer group on the academic performance of students. The finding showed that peer's relationship influence academic performance of students.

Manski (1993), in his article on peer influence as a social interaction postulated that the relationship between an individual's behavior and other group member's behavior comes from three diverse effects. In applying the concepts to the influence of peer group in education, he noted the following behavioral outcome:

a. Endogenous effects (or simultaneous effects) referring to a person's behavior varies with the mean behavior of the peer group. For example, the propensity of a student graduating from a university will be impacted by the proportion of students graduating from the university in the same school.

b. Exogenous effects (or contextual effects), indicating that an individual's action varies with the exogenous characteristics (pre-determined characteristics) of the peer group. For example, the tendency of a student graduating from university can be affected by the average level of mother's education of other students in the university.

c. Correlated effects: when a persons in same group tend to behave similarly because they are subject to a common institutional environment or they share the similar characteristics.

Most literature often refers the shared institutional settings as 'common shocks'. For instance, all students in the same classroom doing well academically may reflect nothing but the high quality of the teacher. A shared characteristic is the other part of correlated effects which arises when individuals tend to self-select into a group with members sharing similar behavior. For example, families that are very supportive of children's education are more likely to sort themselves across schools in order to seek for better peers. Accordingly, research work on peer influence usually models the behavior (outcomes) of an individual (Manski, 2000).

Another study was conducted by Lavy and Schlosser (2007) who examined classroom level peer influence, and find that a greater percentage of female classmates improve both boys and girls academic performance. The study predetermined peer characteristics, such as peer race and gender. Peer influence may be present in the workplace, at school or within the society; it can affect people of all ages. It may affect people in different ways but here, the focus is on the activities of peer group as it influences academic performance of undergraduate students. Peer group may have a positive influence and help to challenge or motivate one to do best. Peer group influence may also result in one doing things that may not fit with ones sense of what is right or wrong. In other words, when peer group makes one do things that people frown at, it is a negative peer influence. Operationally peer group influence is a force exert by people that is pressured by ideas, values and behavior either positively or negatively and always associated with adolescents. Studies have shown that students who do not manage their activities with peer group make lower grades than less socially accepted adolescent (Hartney, in Manski, 1993).

The researcher deem it necessary to look at an area that scholars do no often consider in their study of peer group influence, and that is parents influence on pupils peer group relationship. Taiwo in Olalekan (2016) noted that the first people with whom the child comes in contact with are the parents. They transmit to him their own values of right and wrong at a time when he is not in contact with any other influences. Unless the foundation laid by home is sound and solid, the school has nothing to build upon and the child later becomes a problem not only to his parents but also to the community. It is therefore the home that the child comes from that determines type of group the child would join. In essence a child from home that is well-disciplined would find it difficult to be in a group that comprises of delinquents and if he finds himself in such group, he would refuse to be influenced by their behaviors. In a case where such a child is influenced by the group behavior, the situation at home does not allow him to exhibit it and thus he pretends and become meek in the presence of his parents. It is important for the parents to know a child's friends both at home and at school, in order to achieve this, parents should make themselves more accessible to their children. Hake as quoted in Brown and Larson (2009) was of the opinion that parents must be properly educated on matters of discipline since it is dangerous to be too permissive or too strict. The content of parent education should include the rather special treatment required by the child at the adolescent stage. At the secondary school level, parents should be made to realize that the child is no longer toddler at this stage because he is experiencing a new awareness of the world and he is struggling not only to make a place for himself in his own age group but in the world at large. It is also the task of parents to continue to give good examples to the children. This is important because pupil's imitation rate as discussed earlier is very high and thus copy conduct from the adults. Thus, it is likely that parents who smoke find such behaviors in their children. And as such, the child would not resist such behaviors in 
their children. More so, the child would not resist joining or forming a group of smokers or late nigh keepers which in turn reduces the child's academic performance. This also invariably would have a negative influence on his learning outcome.

Goethe (2001) found out that weak students do better when grouped with other weak students. It shows that student's academic performance improves if they are with the students of their own kind. Sacerdote (2001) found out that grades are higher when students have unusually academically strong peers. The results of Zimmerman (2003) were somehow contradictory to Goethe results but again it proved that student's academic performance depends on number of different factors, it says that weak peers might reduce the performance of strong students. Bankole and Ogunsakin (2015) opine that drug use among students under peer group influence significantly influences academic performance, though in a negative way. Drug use like smoking, alcoholism and other odd behaviors were expression of peers' non-conformity to adult value, while value and moral standard of the peer become increasingly moves away from the family, most especially during their school years. Peer group influence on risk taking behaviors such as substance abuse and sexual activities have been shown to increase the likelihood of affecting academic performance in a negative way Santor et al. in Olalekan (2016). Students learn about what is acceptable in their social group by "reading" their friends' reactions to how they act, what they wear, and what they say. The peer group gives this potent feedback by their words and actions, which either encourages or discourages certain behaviors and attitudes. Anxiety can arise when teens try to predict how peers will react, and this anxiety plays a large role in peer influence. In fact, Burns and Darling (2002) state that self-conscious worrying about how others will react to future actions is the most common way students are influenced by their peers. When a student takes an unpopular stand and goes against the expectations or norms of the peer group, he or she is at risk of being ridiculed. Ridicule is not an easy thing to accept at any age, let alone when you are twelve or thirteen years old. This leads to real peer group influence.

Howard in Steinberg (2005) opined that students have always been exposed to the influence of peer group, but the kinds of influence that they encounter have changed tremendously in the past years. Peer groups can influence everything from what a student chooses to wear to whether or not the student engages in drug related or other delinquent behavior.

\section{Research hypotheses}

The following Null Hypotheses were tested:

$\mathrm{HO}_{1}$ : There is no significant influence of peer group and academic performance of students.

$\mathrm{HO}_{2}$ : There is no significant relationship between peer group and academic performance.

\section{METHODOLOGY}

\section{Participants and design}

The target population used for this study consists of 163 students drawn from five (5) departments in the School of Education and Humanities, Babcock University. This study adopted a mixed methods design incorporating descriptive survey and ex post facto designs. The reason for the use of survey design is because, questionnaires will be administered on peer group and ex post facto design because, raw score data for academic performance that was used for this study was derived from past records of students that constituted the target population for this study.

\section{Instrumentation and data analysis}

The researchers used a self-structured five Likert scale questionnaire as a tool for the collection of data.

The researchers employed Pearson Product Moment correlation coefficient and Linear Regression Analysis to test the null hypotheses at 0.05 level of significance and finally, Statistical Package for Social Sciences (SPSS) was used for data analyzing.

\section{RESULTS}

\section{Demographic presentation}

Results in Table 1 showed that a majority of the respondents $(54.3 \%)$ were female, while $45.7 \%$ of the respondents were male. Thus, we have more female than men participants in this study.

Result in Table 2 showed that the greatest proportion of the respondents $(40.5 \%)$ were between the age brackets of 20 to 23 years. This was followed successively by those who were 16 to 19 years old $(36.2 \%)$, and 24 years and above were (23.3\%). This further shows that this study covered the targeted respondents it was meant for.

\section{Hypotheses testing}

\section{Hypothesis 1}

$\mathrm{HO}_{1}$ : There is no significant influence of peer group on academic performance of student.

Table 3 indicated a significant result $($ Beta $=.537, \mathrm{t}=$ 
Table 1. Gender distribution of participants' demographic variables.

\begin{tabular}{llcc}
\hline Variable & Gender category $(\mathbf{N}=\mathbf{1 1 6})$ & Frequency & Percentage \\
\hline \multirow{2}{*}{ Sex } & Male & 53 & 45.7 \\
& Female & 63 & 54.7 \\
\hline
\end{tabular}

Source: Researchers computation from field survey, 2018.

Table 2. Age distribution of participants' demographic variables.

\begin{tabular}{cccc}
\hline S/No & Age (year) & Frequency & Percentage \\
\hline 1 & $16-19$ & 42 & 36.2 \\
2 & $20-23$ & 47 & 40.5 \\
3 & 24 and above & 27 & 23.3 \\
\hline
\end{tabular}

Source: Researchers computation from field survey, 2018.

Table 3. Linear regression analysis of the influence of peer group on academic performance.

\begin{tabular}{|c|c|c|c|c|c|}
\hline \multirow{2}{*}{ Model } & \multicolumn{2}{|c|}{ Unstandardized co-efficient } & \multirow{2}{*}{$\frac{\text { Standardized co-efficient }}{\text { Beta }}$} & \multirow{2}{*}{$t$} & \multirow{2}{*}{ Sig. } \\
\hline & B & Std. Error & & & \\
\hline (Constant) & .525 & .365 & & 1.440 & .153 \\
\hline Peer Group & .043 & .006 & .537 & 6.799 & .006 \\
\hline
\end{tabular}

Dependent Variable: Academic Performance

Predictors: (Constant), Peer group.

$6.799, p<.05)$, the null hypothesis is consequentially rejected in favor of the conclusion that there is a significant influence of peer group on academic performance of students. Given that $Y$ represent academic performance and $X$ represents peer group, the relevant regression equation that can be used to predict $Y$ from $X=.043 X+.525$.

\section{Hypothesis 2}

$\mathrm{HO}_{2}$ : There is no significant relationship between peer group and academic performance.

Table 4 revealed significant results $(r=.537, p<.05)$. The null hypothesis is therefore rejected and the alternative hypothesis in upheld. It is concluded that there is a significant relationship between Peer group and academic performance.

\section{DISCUSSION}

From hypothesis one above the study found that peer group has a significant influence on academic performance of students. This finding is not in isolation to other findings on the influence of peer group on student academic performance. Zimring (1998) observed that peer influence is the primary contextual factor contributing to student's tendency to make risky decisions. As supported by landau (2002) that students who care about learning are more likely to associate with peers who shares similar interest in learning. However, personal interest and value an individual attaches to an issue also affects the individual's response to change. This may account for Ryan (2002) conclusion that value result in resistance to change, and low value result in receptiveness to change. Peer can influence everything about a student from the choice of what to wear, to engaging in drug related or other behavior.

Results of the findings in hypothesis two elicit that there is a significant relationship between Peer group and academic performance. This is shown above with a significant results $(r=.537)$. The finding is similar to those of Temitope and Christy (2015) who found out that, there is a relationship that exist between peer group and student's academic performance either in the positive or negative way. Positive influence contributed to students' academic performance. However, socialization was among the factors that raised students' self-awareness and cooperation. Additionally, relationships from close friends being girls or boys had been associated with academic performance on one hand; and on the other hand; in changing negative behaviors to positive. Mosha (2017) also collaborated with the results of the present study when he noted in his study the factors that 
Table 4. Correlation matrix for the relationship between peer group and academic performance.

\begin{tabular}{lcc}
\hline & Peer group & Academic performance \\
\hline Peer group & 1 & $.537^{*}$ \\
Academic performance & & 1 \\
\hline
\end{tabular}

${ }^{*}$ Correlation is significant at 0.01 levels (2- tailed).

influenced peer relationship and its effects on students' academic performance as thus: the nature of friends had $(40 \%)$, globalization $(20 \%)$, economic status $(25 \%)$ and sharing academic matters (15\%). It is important to note that nature of friendship students keep has the potential influence on their relationships at the schools rather than academic matters.

\section{CONCLUSION AND RECOMMENDATION}

From the results therefore, this study concludes that, peer group plays an important role in the lives of students. They form a critical part of the social environment of school and also create and maintain a culture different from the home. It is obvious Peer groups are not a fad or a trend, they are around to stay; therefore, Parents, Teachers and Administrators should be on watch-out to identify the types of peer their students move with both in school and outside the home. They should do their best to see that their children relates with friends who can positively influence them and have good impact on their academic performance.

Counselors should play a prominent and leading role in the matter by organizing lectures, seminars, career talk and symposiums that can create positive awareness on influence of peer group on academic performance of undergraduate students.

The following conclusions were drawn from the findings of the study:

1. There is significant influence of peer group on academic performance of student. Therefore school administrators and parents/guardians have a role to play in monitoring the types of peer their students and wards move with both in school and outside the home.

2. There is a significant relationship between Peer group and academic performance. It is clear from the finding that peer does, in fact, have a relatively strong influence over the daily functioning of students and their academic achievement. Therefore the choices those students make regarding their engagement and academic performance in school depends on how they are guided and supported by their parent.

Based on the conclusion of the study, the following recommendations were made:

1. The finding revealed that peer group has an influence on student and such influence could be positive or negative therefore, there is need for teacher to have greater supervision and regulations on students while they are in school this will enhance the type of group the belong to.

2. The government and ministry of education should ensure that trained counselors are posted in all schools and colleges so as to provide preventive counseling services and modify the behaviors of student who perchance have been negatively influenced by peers.

3. School counselors should play a prominent and leading role in the matter of peer group influence by organizing lectures, seminars, career talk and symposiums that can create positive awareness on influence of peer group on academic performance of undergraduate students.

4. School counselors, teachers, parents, and other government agencies should actively participate and get involved in role - modeling of students by introducing informative programs that could educate them about peer group influence and thus, refocus them meaningfully towards excellent academic performance; this could help the development of the nation's academic future.

\section{REFERENCES}

Bankole E. T., and Ogunsakin F. C. (2015). Influence of peer group on academic performance of secondary school students in Ekiti State. International Journal of Innovative Research and Development, 4(1): 324-331.

Brown, B. B., and Larson, J. (2009). Peer relationships in adolescents. In Steinberg, R. M. L. (Ed.), Handbook of adolescent psychology, Contextual influences on adolescent development (Vol. 2, 3rd ed., pp. 74-103).

Burnett, S., Sebastian, C., Cohen Kadosh, K., and Blakemore, S. J. (2011). The social brain in adolescence: Evidence from functional magnetic resonance imaging and behavioural studies. Neuroscience and Bio-behavioral Reviews, 35, 1654-1664.

Burns, A., and Darling, N. (2002). Peer pressure is not peer influence. The Education Digest, 68: 4-6.

Castrogiovanni, D. (2002). Adolescence: Peer groups. Retrieved from http://www.ianr.unl.edu/pubs/family/nf211.htm_on 25-2-2018.

Goethe, G. R. (2001). Peer effects, gender, and intellectual performance among students at a highly selective college: A social comparison of abilities analysis. Presentation Paper-61.

Landau, A. (2002). Peer groups and educational outcomes. Retrieved January 24, 2018.

Lashbrook, J. T. (2000). Fitting in: Exploring the emotional dimension of adolescent pressure. Adolescence, 35(140): 747-757.

Lavy, V., and Shlosser, A. (2007). Mechanisms and Impacts of Gender Peer Effects at School. NBER Working Paper 13292. National Bureau of Economic Research. Cambridge, MA.

Manski, C. F. (1993). Identification of endogenous social effects: The 
reflection problem. The Review of Economic Studies, 60(3): 531-542.

Manski, C. F. (2000). Economic analysis of social interactions. Journal of Economic Perspectives, 14(3), 115-136.

Mosha, M. A. (2017). The influence of peer group on academic performance of adolescent students in secondary schools in Tanzania: Faculty of Education, University of Bagamoyo, Tanzania. Retrieved on 10-03-2018.

Olalekan, A. B. (2016). Influence of peer group relationship on the academic performance of students in secondary schools: A case study of selected secondary schools in Atiba Local Government Area of Oyo State. Global Journal of Human-Social Science, 16, 4.

Ryan, A. M. (2002). Peer groups as a context for the socialization of adolescents' motivation, engagement, and achievement in school. Educational Psychologist, 35: 101-112.

Sacerdote, B. (2001). Peer effects with random assignments: Results for Dartmouth roommates. The Quarterly Journal of Economics, May 2001: MIT Press.

Steinberg, L. (2005). Psychology of adolescents. New York: McGraw.

Steinberg, L. (2008). A social neuroscience perspective on adolescent risk-taking. Developmental Review, 28: 78-106.

Temitope, B. E., and Christy, O. F. (2015). Influence of peer group on academic performance of secondary school students in Ekiti State. International Journal of Innovative Research and Development, 4(1): 324-331.

Zimmerman, G. (2003). Peer Effects in Higher Education. NBER Working Paper No.9501, JEL no 121.

Zimring, F. (1998). American youth violence: Studies in crime and public policy. New York, NY: Oxford University Press.
Citation: Filade, B. A., Bello, A. A., Uwaoma, C. O., Anwanane, B. B., and Nwangburuka, K., (2019). Peer group influence on academic performance of undergraduate students in Babcock University, Ogun State. African Educational Research Journal, 7(2): 81-87. 